
\title{
CResearch Square \\ Potential of Zymomonas mobilis as an electricity producer in ethanol production
}

\section{Bo-Yu Geng}

Shanghai Jiao Tong University

\section{Lian-Ying Cao}

Shanghai Jiao Tong University

\section{Feng Li}

Tianjin University

\section{Hao Song}

Tianjin University

Chen-Guang Liu ( $\nabla$ cg.liu@sjtu.edu.cn )

Shanghai Jiao Tong University https://orcid.org/0000-0003-0343-6304

\section{Xin-Qing Zhao}

Shanghai Jiao Tong University

\section{Feng-Wu Bai}

Shanghai Jiao Tong University

\section{Research}

Keywords: Zymomonas mobilis; Microbial fuel cell (MFC); Biofilm; Extracellular electron transfer; Redox balance

Posted Date: December 16th, 2019

DOI: https://doi.org/10.21203/rs.2.18762/v1

License: (c) (i) This work is licensed under a Creative Commons Attribution 4.0 International License. Read Full License

Version of Record: A version of this preprint was published at Biotechnology for Biofuels on March 5th, 2020. See the published version at https://doi.org/10.1186/s13068-020-01672-5. 


\section{Abstract}

\section{Background}

Microbial fuel cell (MFC) convokes microorganism as workhorse to convert biomass into electricity. However, most well-known electrogenic strains can not directly use glucose to produce valuable products. Zymomonas mobilis, a promising bacterial for ethanol production, owns special Entner-Doudoroff pathway with less ATP and biomass produced and the low energy-coupling respiration, making $Z$. mobilis a potential exoelectrogen.

Results

A glucose-consumed MFC is constructed by inoculating Z. mobilis . The electricity with power density 2.0 $\mathrm{mW} \mathrm{m} \mathrm{-2}$ is derived from the difference of oxidation-reduction potential (ORP) between anode and cathode chambers. Besides, two-type electricity generation is observed as glucose-independent process and glucose-dependent process. For the sake of enhancing MFC efficiency, extracellular and intracellular strategies are implemented. Biofilm removal and addition of c-type cytochrome benefits electricity performance and Tween 80 accelerates the electricity generation. Perturbation of cellular redox balance compromises the electricity output, indicating that redox homeostasis is the principal requirement to reach idea voltage.

\section{Conclusion}

This study identifies potential feature of electricity activity for Z. mobilis and provides multiple strategies to enhance the electricity output. Therefore, additional electricity generation will benefit the technoeconomic viability of the commercial bulk production for biochemicals or biofuels in an efficient and environmentally sustainable manner.

\section{Background}

Microbial electrochemical technologies (MET) have been widely developed and applied in many fields, including microbial fuel cells (MFC), microbial electrosynthesis, and autonomous power sources for sensors, beacons, and seawater desalination. In particular, sustainable MFC takes advantage of microorganisms as biocatalyst to produce electricity from various organic substances[1,2]

Electro-active microorganisms are also known as exoelectrogens such as well-studied model strains Geobacter sulfurreducens and Shewanella oneidensis[3, 4]. Through electron transport chain, these bacteria pump out electrons to the environment for obtaining energy. In fact, instead of oxygen, metal ion or electrode are more likely to be final electron acceptors via contact-based or shuttles-mediated extracellular electron transfer (EET) pathway. Highly effective EET enables $G$. sulfurreducens and $S$. oneidensis to be promising strains for MFC $[5,6]$. Unfortunately, both of them can not directly use the most common carbon source - glucose resulted in limited substrate spectrum. Hence, several strategies 
have been demonstrated to make broad range of carbon source available for them, such as introducing exogenous pathways and co-cultivation with other strains[7, 8, 9]. Besides, neither wild type nor engineered strains own an ability to produce valuable metabolites, which restricts the application of electro-active microorganism in view of economic benefits.

Zymomonas mobilis is an efficient ethanol-producing strain because of its unique Entner-Doudoroff pathway with less ATP and biomass produced for more sugar to be used for ethanol production, which achieves higher observed yield and higher ethanol productivity than Saccharomyces cerevisiae[10, 11]. Interestingly, the special respiratory chain on membrane made $Z$. mobilis a potential exoelectrogen. The membrane contains an active branched respiratory chain, with type II NADH dehydrogenase, coenzyme Q10, cytochrome BD and several c-type cytochrome as terminal oxidase, together with some minor or still unidentified constituents[12,13]. Although ethanol fermentation and respiration are the major consumers of NADH in Z. mobilis catabolism, this sort of respiration chain with low energy-coupling serves for more functions than oxidative phosphorylation and ATP production. Besides, not like yeast, transition from anaerobic to aerobic growth conditions can't improve Z. mobilis biomass yield[14, 15], revealing that oxygen is not the indispensable electron acceptor. Hence, low energy-coupling respiratory chain may generate electricity by offering electrode as an electron acceptor in MFC.

Oxidation-reduction potential (ORP) is an indicator of electron activities during fermentation, which provides a real-time information about redox status of external environment[16, 17]. Commonly, high ORP indicates a oxidative status and low ORP signifies a reductive status. A significant ORP decline was observed during $Z$. mobilis fermentation due to reducing external environment formed via cell metabolism. Thus, the ORP difference between cathode chamber within oxidative solution and anode chamber within $Z$. mobilis become a kind of driving force to generate the electricity power. Simultaneously, Z. mobilis is able to convert glucose to electricity power and ethanol without complicated genetic engineering technologies. Although an electrochemical analysis had been done in a cell-free system of $Z$. mobilis, electricity generation ability of whole cell was not measured so far[18].

In this study, Z. mobilis was evaluated on electrochemical performance during ethanol production, and some strategies were also undertaken to improve the voltage output, such as removal of biofilm, EET pathway enhancement and change of intracellular redox balance.

\section{Results And Discussion}

\section{Electricity generation by Z. mobilis ZM4}

During ethanol fermentation by Z. mobilis ZM4, the ORP value of broth kept decreasing in the initial $36 \mathrm{~h}$, followed by a slightly recovery until $48 \mathrm{~h}$ (Figure 1A). It has been reported that the glucose consumption rate was the main cause for the altered ORP[20]. Before $36 \mathrm{~h}$, rapid glucose consumption, attributed to active metabolism, tended to release and accumulate the reducing power from the substrate, which consequently pull down the ORP value. Afterward, cell lysis started the oxidized compounds release, 
which led to a little bit restoration of ORP. Therefore, Z. mobilis has potential to build up an reducing environment and form the ORP difference to produce electricity in MFC.

To further identify the potential capacity of electricity generation for Z. mobilis ZM4, OCV and WV were showed in the Figure 2A. Compared to medium-loaded MFC with stable voltage, ZM4-inoculated MFC exhibited a significant voltage output, which increased rapidly and peaked at $30 \mathrm{~h}$, and then kept at high level. The maximal WV was about three-fold higher than that of the medium-loaded MFC, which meant that ZM4 was able to yield more electrons to enhance electricity generation. However, due to inefficient electron generation and transfer, the voltage output of ZM4 was relative lower than other well-known exoelectrogens[3, 4].

Cyclic voltammetry was conducted to reveal the redox reaction that occurred in the equipment. As shown in Figure 2B, a prominent redox peak appeared around $-0.18 \mathrm{~V}$ in medium-loaded MFC while the redox peak moved to around $-0.29 \mathrm{~V}$ in ZM4-inoculated MFC, which was caused by the direct involvement of conductive $c$-type cytochromes. These changed peaks indicated that the mechanism of extracellular electron transfer was different from medium mediated ones. To further investigate electrochemical performance, the polar curve was obtained (Figure 2C). Compared with the power generated in uninoculated MFC, ZM4-inoculated MFC exhibited a 2-fold higher maximum power density of approximately $2.0 \mathrm{~mW} / \mathrm{m}^{2}$.

Ethanol production was monitored in an open circuit MFC, a closed circuit MFC, and flasks. Because of no significant difference among these conditions, electricity generation showed no competition with ethanol production for ZM4(Figure 1B). An energy balance was calculated to clarify the energy flow during power generation and ethanol production. Approximately $86 \%$ of the total energy was captured by ethanol (Figure 1C). By establishing the MFC equipment, approximately $3 \%$ of the energy was derived from the internal energy in the form of electricity. Compared with Shewanella oneidensis, ZM4's recovered electricity energy was 80 -fold lower[21]. But considering the energy captured by ethanol, the total generated energy of ZM4 was still significant.

\section{The mechanism of electricity generation}

According to Figure 3, The specific WV varied with the concentration of glucose. As an electron donor of ZM4-inoculated MFC, a higher glucose concentration would yield more electrons. Hence, MFC with 150 $\mathrm{g} / \mathrm{L}$ glucose exhibited the highest voltage output $72.3 \mathrm{mV}$ per $\mathrm{OD}_{600}$, while as glucose concentration decreased to $20 \mathrm{~g} / \mathrm{L}$, there was only $23.6 \mathrm{mV}$ voltage output.

Additionally, the specific WV also varied over time. From 12 to $60 \mathrm{~h}$, the specific WV increased and peaked at $30 \mathrm{~h}$, followed by a slight regression. Based on the results in section 3.1, the ORP difference was formed by reducing compounds accumulation in the broth via consuming the substrate by Z. mobilis. Therefore, the glucose consumption rate can be considered as a main pointer for electricity generation. Interestingly, another voltage peak appeared between 0 and $12 \mathrm{~h}$, when glucose was not used at all by microorganism, indicating that electricity generation was independent of glucose utilization before $12 \mathrm{~h}$. 
Accordingly, the entire electricity generation could be divided into two types: a glucose-independent process and a glucose-dependent process.

For better understanding of two-type electricity generation, data scaling was adopted to normalize the variable range of WV at different glucose concentrations. In the left-bottom area of Figure 4A, the WV increased sharply when the glucose consumption rate remained unchanged, signifying that a glucoseindependent electricity generation process occurred in the lag growth phase. In the right part of Figure 4A, representing the exponential growth phase, the WV obeyed positive linearity with the glucose consumption rate. In the left top area of Figure 4A, ZM4 entered a stationary growth phase, when two types of electricity generation simultaneously emerged. Furthermore, scatter diagrams of other initial glucose concentrations also showed the similar trends to $100 \mathrm{~g} / \mathrm{L}$, confirming a two-type process was a common phenomenon for ZM4-inoculated MFC, and that the glucose consumption rate was the direct driver of electricity generation progress.

Since the increased voltage during $0-12 \mathrm{~h}$ was independent of glucose uptake, the supernatant should contain some chemicals that contribute to the electricity generation. To verify this hypothesis, supernatants of broth at $6 \mathrm{~h}$ and $30 \mathrm{~h}$ were added in MFC (Figure 4B). The electricity performance of the supernatant at $6 \mathrm{~h}$ was restored immediately, but the supernatant at $30 \mathrm{~h}$ maintained basal level. Hence, the glucose consumption rate was the only contributor to electricity generation at $30 \mathrm{~h}$. While the supernatant was the key driving force for MFC at $6 \mathrm{~h}$, as the removal of cells did not strongly influence electricity performance. Although Z. mobilis cells cease growth and glucose usage during 0-12 h, they continue to release reducing substances, leading to the ORP difference and voltage output. Meanwhile, those reducing substances could be depleted because of low voltage output in the supernatant without cells at $30 \mathrm{~h}$.

In addition, according to Figure 4C, once oxygen was sparged into the supernatant at $6 \mathrm{~h}$, extra voltage generated by reducing substances were vanished, which confirmed the fact that reducing substances contributing to electricity generation could be eliminated by oxygen. In contrast, sparging oxygen at $30 \mathrm{~h}$ had no influence on the electrical properties, indicating the depletion of these reducing substances. Overall, the cooperation between the reducing substances in supernatant and glucose consumption by cells contribute to the total electricity generation.

\section{Improvement of MFC by biofilm removal}

Previous research showed that biofilm attached on the electrode has significant influence on electricity production[22, 23]. Concerning ability of ZM4 to form a biofilm on hydrophobic surfaces[24], biofilm formation on carbon cloth and evaluation of its role in electrogenesis were undertaken.

According to Figure 5A, the biofilm proliferated between 6-30 $\mathrm{h}$ and remained stable after it reached the maximum. Meanwhile, the charge transfer resistance $\left(R_{c t}\right)$ of the electrode calculated by EIS decreased from 0-30 h. As soon as the biofilm ceased growing, $R_{\mathrm{ct}}$ was restored to its original level. To elucidate the exact relationship between $\mathrm{R}_{\mathrm{ct}}$ and the biofilm, the bacterial viability, defined as the ratio of live cells in 
biofilm, was quantified at different time points. Live cells dominated in the biofilm before $30 \mathrm{~h}$, but as the biofilm continued growing, the number of dead cells began to increase and exceeded live cells at $60 \mathrm{~h} . \mathrm{R}_{\mathrm{ct}}$ rose as the viability of cells dropped. The dead cells were not only capable of electricity generation, but also hampered the electron transfer process on the electrode surface[25, 26]. Therefore, the rise of charge transfer resistance at the later phase results from the continuously decreasing viability.

To prevent increased resistance, the biofilm attached to the electrode was cleared at $0,6,30$, and $60 \mathrm{~h}$ (Figure 5A). There was no significant difference in $R_{c t}$ caused by the biofilm between the attached and detached electrode until $60 \mathrm{~h}$. The $\mathrm{R}_{\mathrm{ct}}$ of the detached electrode was almost half of the attached electrode at $60 \mathrm{~h}$, indicating that the removal of the biofilm dominated by dead cells helps enhance electron transfer to the electrode.

Due to positive effect on decreased resistance, biofilm removal was performed in three repeated batches to investigate long-term influence of biofilms on electrical performance. In each batch, the electrode was rinsed to detach biofilm when glucose was exhausted. According to Figure 5B, in the first two batches, the electricity generation of the detachment and attachment groups were maintained at the same level. But the WV of the detachment group was $10 \%$ higher than that in the attachment group in the third batch.

Given the biofilm and charge transfer resistance, although biofilm in the attachment group grew continuously due to the replenishment of fresh medium during the first two batches, the limited quantity of biofilm remained incapable of significantly influencing resistance and electricity performance. In the third batch, the entire surface of electrode had been covered by accumulated biofilm, which interrupted the electron transfer process resulting in a sharp rise in resistance. Hence, biofilm removal increased the $W V$ in the third batch. However, this change was subtle due to the insufficient electricity generation ability of ZM4. Therefore, other strategies should be implemented to strengthen the EET.

\section{Improvement of MFC by EET enhancement}

Frequently, the EET pathway is a bottleneck for further improving the voltage output of exoelectrogens[27]. It consists of an indirect electron shuttle-meditated pathway[28] and the direct pathways, including appendages[29], nanowires[30] and c-type cytochrome[31]. Hence, adding electron shuttles and $c$-type cytochrome was implemented to enhance the EET pathway. To exclude the influence of the medium, voltage improvement ratios of ZM4 $\left(R_{o s}\right.$ and $\left.R_{w s}\right)$ and reagents $\left(R_{o r}\right.$ and $\left.R_{w r}\right)$ were adopted to evaluate the contribution of the bacterial and the reagents to voltage respectively.

Figure 6A shows that methylene blue, neutral red, and TEMPOL significantly influenced the electricity performance: there was a noticeable increase on $R_{w r}$ of methylene blue and $R_{o r}$ of neutral red, and a prominent decline on $\mathrm{R}_{\mathrm{or}}$ of TEMPOL. However, without inoculation of ZM4, these changes could still be achieved by adding these electron shuttles only. In term of the voltage improvement ratio of ZM4 ( $R_{\text {os }}$ and $R_{w s}$ ) (Figure 6B), the cells did not indicate an enhanced ability to generate electricity with the addition of electron shuttles that showed significant changes in Figure 6A. However, c-type cytochrome promoted 
ZM4 to output much more voltage ( $R_{\mathrm{os}}$ and $\mathrm{R}_{\mathrm{ws}}$ were both improved). Meanwhile, $c$-type cytochrome has less influence on MFC ( $R_{o r}$ and $R_{w r}$ remained nearly unchanged). Therefore, instead of an indirect electron shuttle-mediated pathway, enhancing direct electron transfer could significantly benefit the electricity performance, which supported the CV measurement results in reported in section 3.1 that the main EET mechanism was direct involvement of conductive $c$-type cytochrome.

In addition, improving cell membrane permeability was also tried to enhance the transport of electron shuttles across cell membranes and achieve more efficient EET[32]. Tween 80 as a surfactant with concentration of $0,5,20$, and $80 \mathrm{mg} / \mathrm{L}$ were chosen to increase permeability of ZM4[33]. Figure 7 shows that low addition ( 5 and $20 \mathrm{mg} / \mathrm{L}$ ) of Tween promoted the OCV after $24 \mathrm{~h}$, but the highest concentration $(80 \mathrm{mg} / \mathrm{L})$ inhibited OCV. The results reflected that appropriate Tween 80 enhanced the transport of electron shuttles. On the other hand, with the addition of Tween 80 , WV reached peaks earlier, but the entire. Because the total electricity power is determined by the available electron pool, which is not closely related to the surfactant. Hence, improving the total quantity of electrons is the key factor for enhancing the whole electricity generation(E-supplementary data for this work can be found in e-version of this paper online)

\section{Improvement of MFC by intracellular redox homegeneis}

Commonly, electrons were stored in cells in form of NADH[34]. In theory, increasing ratio of NADH to $\mathrm{NAD}^{+}$could help elevate electron pool to enhance voltage output[35]. Adding NAD ${ }^{+}$precursor nicotinic acid (NA) and nicotinamide (NM), or overexpressing cofactor related genes (ZMO0899, ZMO1116, $Z M 01885)$ were adopted. Figure 8 revealed that these two methods are successful to alter ratio of $\mathrm{NADH} / \mathrm{NAD}^{+}$: precursors addition and overexpressing ZM01116 (Glutamate synthase: reduce NAD ${ }^{+}$to $\mathrm{NADH}$ and increase the ratio of $\mathrm{NADH} / \mathrm{NAD}^{+}$) decreased the ratio while overexpressing $Z M 00899\left(\mathrm{NAD}^{+}\right.$ synthase: increase the pool of $\mathrm{NAD}(\mathrm{H} /+)$ and $Z M 01885$ (NADH oxidase: oxidize $\mathrm{NADH}$ to $\mathrm{NAD}^{+}$and decrease the ratio of $\mathrm{NADH} / \mathrm{NAD}^{+}$) improved it. Because these genes functions were results of homologous blast, they may perform opposed functions in ZM4. Unfortunately, the maximum WV decreased with addition of nicotinic acid or nicotinamide and overexpressing redox-related genes. Owing to $Z$. mobilis sensitive to the intracellular redox change, altered ratio of $\mathrm{NADH} / \mathrm{NAD}^{+}$possibly inhibited electricity performance. Therefore, maintaining redox homogeneis is the precondition for improving voltage output of ZM4. Besides, this fact emphasized that if gene manipulation was adopted to enhance electricity performance, keeping redox balance should be focused, because the voltage improvement resulted from gene manipulation may be counteracted by the negative effect of redox imbalance during this modification process.

\section{Improvement of MFC by the strategies combination}

To further upgrade voltage output, cooperation of several effective methods (biofilm removal, addition of $c$-type cytochrome and Tween 80) were also tested. Figure 9 revealed that with addition of $c$-type cytochrome, electricity power increased by $30 \%$ (from 2.0 to $2.6 \mathrm{~mW} / \mathrm{m}^{2}$ ) and Tween 80 helped reduce the 
time needed to reach the WV climax for MFC by about $6 \mathrm{~h}$. Any treatment involving these two methods obtained the positive effect on electricity generation. However, biofilm removal did not affect MFC obviously. As previous discussion in section 3.3, only repeated batch fermentation was able to influence WV in Z. mobilis-inoculated MFC. Enough accumulation and long-term growth leads to more dead cells trapped in the biofilm, thus refreshing the biofilm with short fermentation time can't exhibit significant improvement of electricity production. Therefore, combination of $c$-type cytochrome and Tween 80 improved power density and accelerated the entire electricity generation simultaneously showing that advantages of these two methods could be superposed to benefit electricity performance more.

\section{Conclusions}

A Z. mobilis-inoculated bioelectrochemical system was constructed, which was directly driven by ORP difference and obtained a considerable bioelectricity generation $\left(2.0 \mathrm{~mW} / \mathrm{m}^{2}\right)$. Two-types electricity generation was observed as glucose-independent process and process. Several strategies were implemented to improve the performance. Biofilm removal and $c$-type cytochrome helped cells to promote electricity generation and Tween 80 accelerated voltage output. Redox balance was identified to be the precondition for higher electricity output. The combination of multiple methods realized further improvement of power. Overall, Z. mobilis was proven to be a promising strain for energy production in an efficient and environmentally sustainable manner.

\section{Methods}

\section{Strains, medium, and cultivation}

Wild type and genetic manipulated Z. mobilis ZM4 were cultivated statically at $30^{\circ} \mathrm{C}$ for seeds. A loop of colonies was scratched from solid plate and inoculated into $100 \mathrm{~mL} \mathrm{RMG2} \mathrm{(g/L):} 10$ yeast extract, 2 $\mathrm{KH}_{2} \mathrm{PO}_{4}$, and 20 glucose. After $18 \mathrm{~h}, 14 \mathrm{~mL} \mathrm{OD}_{600}=1$ culture was transferred into $126 \mathrm{~mL} \mathrm{RMG10} \mathrm{(g/L):}$ 10 yeast extract, $2 \mathrm{KH}_{2} \mathrm{PO}_{4}$, and 100 glucose. $20 \mu \mathrm{g} / \mathrm{mL}$ tetracycline was added in RMG medium if using engineered strains to prevent the loss of expression vectors.

\section{MFC setup and ORP monitoring}

Carbon cloth was used as the electrodes for both anode $(2.5 \mathrm{~cm} \times 2.5 \mathrm{~cm})$ and cathode $(2.5 \mathrm{~cm} \times 3 \mathrm{~cm})$. The H-type MFC was separated by Nafion 117 membrane, which was pretreated in $1 \mathrm{~mol} / \mathrm{L} \mathrm{HCl}$ for overnight and kept in sterile distilled water before $\mathrm{H}$-type MFC setup. $140 \mathrm{~mL} \mathrm{~K}{ }_{3}\left[\mathrm{Fe}(\mathrm{CN})_{6}\right](50 \mathrm{mmol} / \mathrm{L})$ and RMG10 were supplemented to cathode chamber and anode chamber respectively. The MFC was incubated at $30^{\circ} \mathrm{C}$ statically. The open circuit voltage (OCV) and the work voltage (WV) with a $2 \mathrm{~K} \Omega$ resistor were recorded. An ORP electrode (model: Pt4805-DPASSC-K8S/225, Mettler Toledo, Switzerland) was inserted into the fermentor to monitor ORP of medium, and a handheld ORP monitor (MT-8050) was used to measure ORP in MFC. 


\section{Quantification of metabolites}

The sample was centrifuged at $8000 \mathrm{rpm}$ for $2 \mathrm{~min}$ to collect the supernatant, which was used to quantify glucose and ethanol by HPLC (Waters 1525) with a column (Aminex HPX-87 H $300 \times 7.8$ mm, Bio-Rad, USA) and an RI detector (Waters 2414). The mobile phase consisted of $4 \mathrm{mmol} / \mathrm{L} \mathrm{H}_{2} \mathrm{SO}_{4}$, and the flow rate was set at $0.6 \mathrm{~mL} / \mathrm{min}$. The temperatures for column and RI detector were set at $50^{\circ} \mathrm{C}$.

\section{Bio-electrochemical analysis}

Cyclic voltammetry (CV) was performed on a $\mathrm{CHI} 1000 \mathrm{C}$ multichannel potentiostat (CH Instrument, Shanghai, China) and was conducted on a three-electrode configuration with the anode as the working electrode, the cathode as the counter electrode, and the $\mathrm{Ag} / \mathrm{AgCl}$ (vs. SHE) as the reference electrode. Different resistors were used to obtain the maximum power density and the polarization curves. Electrochemical impedance spectroscopy (EIS) was performed to evaluate the internal resistance by using a three-electrode system. Alternating current potential (maximum amplitude of $10 \mathrm{mV}$ ) in the frequency range of $100 \mathrm{kHz}-5 \mathrm{~Hz}$ was applied to EIS experiments and the results were plotted in the form of Nyquist curve where the charge transfer resistance $\left(R_{c t}\right)$ was calculated by fitting the measured impedance data to an equivalent circuit by $Z$ view software.

\section{Energy flow calculation}

Combustion heat was calculated to represent the energy stored in substance. The combustion heat of glucose and ethanol are $-2804 \mathrm{~kJ} / \mathrm{mol}$ and $-1366.8 \mathrm{~kJ} / \mathrm{mol}$, respectively. The combustion heat of biomass and yeast extract were estimated by Mendeleev's empirical formula. Their elemental compositions were measured by Elemental Analysis (Flash Smart, ThermoFisher, China). After calculation, the estimated combustion heats of biomass and yeast extract were $18654.11 \mathrm{~kJ} / \mathrm{kg}$ and $15473.58 \mathrm{~kJ} / \mathrm{kg}$, respectively. The electricity power released by MFC was calculated by integrating the power density with time.

\section{Quantitative analysis of biofilm}

Six wells plates were used to hold carbon cloth as platform for biofilm formation. After cultivated for 0,6 , $30,60 \mathrm{~h}$, carbon clothes with biofilm were picked out and soaked in crystal violet for $20 \mathrm{~min}$, and then were rinsed with water for two times and dissolved in $1 \mathrm{~mL} 95 \%$ ethanol for $\mathrm{OD}_{595}$ measurement. Biofilm attaching electrodes was collected at $0,6,30$, and $60 \mathrm{~h}$ to test their viability with LIVE/DEAD BacLight ${ }^{\mathrm{TM}}$ Bacterial Viability and Counting Kit. Viability was calculated by photos of fluorescence microscope. $\mathrm{NADH} / \mathrm{NAD}^{+}$ratio at $24 \mathrm{~h}$ was obtained by Beyotime ${ }^{\mathrm{TM}} \mathrm{NAD}^{+} / \mathrm{NADH}$ measurement kit.

\section{Addition of reagents}

Electron shuttles, surfactant, and NAD ${ }^{+}$precursors were shown in Table 1:

Table 1 The chemicals used in this study 


\begin{tabular}{lll}
\hline Name & Sort & Concentration \\
\hline Methylene blue & Electron shuttle & $1,5,10 \mathrm{mmol} / \mathrm{L}$ \\
Neutral red & Electron shuttle & $1,5,10 \mathrm{mmol} / \mathrm{L}$ \\
Humic acid & Electron shuttle & $1,10,20 \mathrm{mg} / \mathrm{L}$ \\
1,4-butanedisulfonate & Electron shuttle & $1,5,10 \mathrm{mmol} / \mathrm{L}$ \\
Methyl naphthoquinone & Electron shuttle & $1,5,10 \mathrm{mmol} / \mathrm{L}$ \\
TEMPOL & Electron shuttle & $1,5,10 \mathrm{mmol} / \mathrm{L}$ \\
Riboflavin & Electron shuttle & $1,5,10 \mathrm{mmol} / \mathrm{L}$ \\
$c$-type cytochrome & Cytochrome protein & $0.1,0.5,1 \mathrm{mmol} / \mathrm{L}$ \\
Tween 80 & Surfactant & $5,20,80 \mathrm{mg} / \mathrm{L}$ \\
Nicotinic acid & NAD ${ }^{+}$precursor & $1,10 \mathrm{mmol} / \mathrm{L}$ \\
Nicotinamide & NAD ${ }^{+}$precursor & $1,10 \mathrm{mmol} / \mathrm{L}$ \\
\hline & & \\
\hline
\end{tabular}

\section{Mathematical analysis}

Scaling values is a normalization to restrict range of values between 0 to 1 . such as values of WV and glucose consumption rate.

Scaled $V=\left(V-V_{\min }\right) /\left(V_{\max }-V_{\min }\right) \quad$ (Equation 1)

The improvement ratio of OCV and WV based on electron shuttle or cells were adopted to estimate their effects on electricity generation. 

$\mathrm{R}_{\mathrm{or}}=\left(0-0_{\mathrm{S}}\right) / \mathrm{O}_{\mathrm{C}}$
(Equation 2)
$\mathrm{R}_{\mathrm{wr}}=\left(\mathrm{W}-\mathrm{W}_{\mathrm{S}}\right) / \mathrm{W}_{\mathrm{C}}$
(Equation 3)
$\mathrm{R}_{\mathrm{o}}=\left(\mathrm{O}_{\mathrm{S}}-\mathrm{O}_{\mathrm{C}}\right) / \mathrm{O}_{\mathrm{C}}$
(Equation 4)
$\mathrm{R}_{\mathrm{w}}=\left(\mathrm{W}_{\mathrm{S}}-\mathrm{W}_{\mathrm{C}}\right) / \mathrm{W}_{\mathrm{C}}$
(Equation 5)
$\mathrm{R}_{\mathrm{os}}=\left(\mathrm{O}-\mathrm{O}_{\mathrm{R}}\right) / \mathrm{O}_{\mathrm{C}}-\mathrm{R}_{\mathrm{o}}$
(Equation 6)
$\mathrm{R}_{\mathrm{ws}}=\left(\mathrm{W}-\mid \mathrm{W}_{\mathrm{R}}\right) / \mathrm{W}_{\mathrm{C}}-\mathrm{R}_{\mathrm{w}}$
(Equation 7)

The meanings of these symbols were clarified in Table 2 :

Table 2 Definitions of symbols 


\begin{tabular}{cl}
\hline Symbol & \multicolumn{1}{c}{ Meaning } \\
\hline $\mathrm{R}_{\mathrm{or}}$ & OCV improvement ratio of reagents \\
$\mathrm{R}_{\mathrm{OS}}$ & OCV improvement ratio of cells with reagents \\
$\mathrm{R}_{\mathrm{O}}$ & OCV improvement ratio of cells \\
$\mathrm{R}_{\mathrm{wr}}$ & WV improvement ratio of reagents \\
$\mathrm{R}_{\mathrm{ws}}$ & WV improvement ratio of cells with reagents \\
$\mathrm{R}_{\mathrm{W}}$ & WV improvement ratio of cells \\
$\mathrm{O}_{\mathrm{R}}$ & Maximum OCV of reagents \\
$\mathrm{O}$ & Maximum OCV of cooperation of reagents and cells \\
$\mathrm{O}_{\mathrm{S}}$ & Maximum OCV of cells \\
$\mathrm{O}_{\mathrm{C}}$ & Maximum OCV of RMG10 medium \\
$\mathrm{W}_{\mathrm{R}}$ & Maximum WV of reagents \\
$\mathrm{W}$ & Maximum WV of cooperation of reagents and cells \\
$\mathrm{W}_{\mathrm{S}}$ & Maximum WV of cells \\
$\mathrm{W}_{\mathrm{C}}$ & Maximum WV of RMG10 medium \\
\hline
\end{tabular}

\section{DNA preparation, manipulation, and transformation}

According to database in Kyoto Encyclopedia of Genes and Genomes (KEGG), the genes involved in cofactor (NADH/NAD ${ }^{+}$and NADPH/NADP ${ }^{+}$) were selected to overexpress in Z. mobilis ZM4, including ZM00899 (NAD ${ }^{+}$synthase), ZM01116 (glutamate synthase) and ZM01885 (NADH oxidase). These genes were amplified from ZM4 genome and ligated with native gap prompter and linearized vector pHW20a plasmid through homologous recombination. The newly constructed plasmids were identified 
and confirmed by PCR, restriction endonucleases digestions, and DNA sequencing. After DNA demethylation, the vectors were successfully transformed into electro-competent $Z$. mobilis cells by electroporation through an electrical pulse created by Gene Pulser ${ }^{\circledR}$ II Electroporator (Bio-Rad) set at 25 $\mu \mathrm{F}, 1.60 \mathrm{kV}$, and $2000 \Omega[19]$.

\section{Abbreviation}

MET: Microbial electrochemical technologies; MFC: Microbial fuel cell; ORP: Oxidation-Reduction potential; EET: Extracellular electron transfer; $\mathrm{R}_{\mathrm{ct}}$ : Charge transfer resistance; NA: Nicotinic acid; NM: Nicotinamide; NADH: Nicotinamide adenine dinucleotide; OCV: Open circuit voltage; WV: work voltage; CV: Cyclic voltammetry; EIS: Electrochemical impedance spectroscopy.

\section{Declarations}

\section{Ethics approval and consent to participate}

Not applicable.

\section{Consent for publication}

All authors consented to the publication of this work.

\section{Availability of data and materials}

All data generated or analyzed during this study are included in this published article and supplementary materials..

\section{Competing interests}

The authors declare that they have no competing interests

\section{Funding}

This work was financially supported by National Key R\&D Program of China from Ministry of Science and Technology of the People's Republic of China [grant number 2018YFB1501401], National Natural Science Foundation of China [grant number 21978167], and the Natural Science Foundation of Shanghai [grant number 18ZR1420700].

\section{Authors' contributions}

BYG completed major experiments and wrote the manuscript. FL, HS and CGL participated in the experiment design. CGL, XQZ and FWB helped analyze the result of this work. CGL and LYC revised the first draft of the article. All of authors read and approved the final manuscript. 


\section{Acknowledgments}

We thank Jia-Wei Zhang, Xue Zhang for experiment work and helpful discussions. We are also grateful to Qian Liu for her analytical support.

\section{References}

1. Wang H, Luo H, Fallgren PH, Jin S, Ren ZJ. Bioelectrochemical system platform for sustainable environmental remediation and energy generation. Biotechnology Advances. 2015;33(3-4):317-34.

2. Moqsud MA, Omine K, Yasufuku N, Hyodo M, Nakata Y. Microbial fuel cell (MFC) for bioelectricity generation from organic wastes. Waste Management. 2013;33(11):2465-9.

3. Li W-C, Li X, Zhu J-Q, Qin L, Li B-Z, Yuan Y-J. Improving xylose utilization and ethanol production from dry dilute acid pretreated corn stover by two-step and fed-batch fermentation. Energy. 2018; 157:877-85.

4. Dantas JM, Morgado L, Aklujkar M, Bruix M, Londer YY, Schiffer M, et al. Rational engineering of Geobacter sulfurreducens electron transfer components: a foundation for building improved Geobacter-based bioelectrochemical technologies. Frontiers in Microbiology. 2015;6.

5. Fredrickson JK, Romine MF, Beliaev AS, Auchtung JM, Driscoll ME, Gardner TS, et al. Towards environmental systems biology of Shewanella. Nature Reviews Microbiology. 2008;6(8):592-603.

6. Lovley DR, Ueki T, Zhang T, Malvankar NS, Shrestha PM, Flanagan KA, et al. Geobacter. The Microbe Electric's Physiology, Ecology, and Practical Applications. In: Poole RK, editor. Advances in Microbial Physiology, Vol 59. Advances in Microbial Physiology. 592011. p. 1-100.

7. Choi D, Lee SB, Kim S, Min B, Choi I-G, Chang IS. Metabolically engineered glucose-utilizing Shewanella strains under anaerobic conditions. Bioresource Technology. 2014;154:59-66.

8. Liu Y, Ding M, Ling W, Yang Y, Zhou X, Li B-Z, et al. A three-species microbial consortium for power generation. Energy \& Environmental Science. 2017;10(7):1600-

9. Lin T, Bai X, Hu Y, Li B, Yuan Y-J, Song H, et al. Synthetic Saccharomyces cerevisiae-Shewanella oneidensis consortium enables glucose-fed high-performance microbial fuel cell. Aiche Journal. 2017;63(6):1830-8.

10. Rogers PL, Jeon YJ, Lee KJ, Lawford HG. Zymomonas mobilis for fuel ethanol and higher value products. In: Olsson L, editor. Biofuels. Advances in Biochemical Engineering-Biotechnology. 1082007. p. 263-88.

11. Gunasekaran P, Raj KC. Ethanol fermentation technology - Zymomonas mobilis. Current Science. 1999;77(1):56-68.

12. Balodite E, Strazdina I, Galinina N, McLean S, Rutkis R, Poole RK, et al. Structure of the Zymomonas mobilis respiratory chain: oxygen affinity of electron transport and the role of cytochrome $\mathrm{C}$ peroxidase. Microbiology-Sgm. 2014;160:2045-52. 
13. Kalnenieks U, Galinina N, Irbe I, Toma M. Energy coupling sites in the electron transport chain of Zymomonas mobilis. FEMS Microbiology Letters. 1995;133(1-2):99-104.

14. Bringer S, Finn RK, Sahm H. Effect of oxygen on the metabolism of Zymomonas mobilis. Archives of Microbiology. 1984;139(4):376-81.

15. Pankova LM, Shvinka JE, Beker MJ. Regulation of intracellular $\mathrm{H}+$ balance in Zymomonas mobilis 113 during the shift from anaerobic to aerobic conditions. Applied Microbiology \& Biotechnology. 1988;28(6):583-8.

16. Liu C-G, Wang N, Lin Y-H, Bai F-W. Very high gravity ethanol fermentation by flocculating yeast under redox potential-controlled conditions. Biotechnol Biofuels. 2012;5.

17. Liu C-G, Xue C, Lin Y-H, Bai F-W. Redox potential control and applications in microaerobic and anaerobic fermentations. Biotechnology Advances. 2013;31(2):257-65.

18. Jeon BY, Hwang TS, Park DH. Electrochemical and Biochemical Analysis of Ethanol Fermentation of Zymomonas mobilis KCCM11336. J Microbiol Biotechnol. 2009;19(7):666-74.

19. Xia J, Liu C-G, Zhao X-Q, Xiao Y, Xia X-X, Bai F-W. Contribution of cellulose synthesis, formation of fibrils and their entanglement to the self-flocculation of Zymomonas mobilis. Biotechnol Bioeng. 2018;115(11):2714-25.

20. Liu C-G, Lin Y-H, Bai F-W. Development of redox potential-controlled schemes for very-high-gravity ethanol fermentation. J Biotechnol. 2011;153(1-2):42-7.

21. Li F, An X, Wu D, Xu J, Chen Y, Li W, et al. Engineering Microbial Consortia for High-Performance Cellulosic Hydrolyzates-Fed Microbial Fuel Cells. Frontiers in Microbiology. 2019;10.

22. Ramasamy RP, Ren Z, Mench MM, Regan JM. Impact of initial biofilm growth on the anode impedance of microbial fuel cells. Biotechnol Bioeng. 2008;101(1):101-8.

23. Zhang L, Zhu X, Li J, Liao Q, Ye D. Biofilm formation and electricity generation of a microbial fuel cell started up under different external resistances. Journal of Power Sources. 2011;196(15):6029-35.

24. Todhanakasem T, Sangsutthiseree A, Areerat K, Young GM, Thanonkeo P. Biofilm production by Zymomonas mobilis enhances ethanol production and tolerance to toxic inhibitors from rice bran hydrolysate. New Biotechnology. 2014;31(5):451-9.

25. Islam MA, Woon CW, Ethiraj B, Cheng CK, Yousuf A, Khan MMR. Correlation of power generation with time-course biofilm architecture using Klebsiella variicola in dual chamber microbial fuel. Int $\mathrm{J}$ Hydrog Energy. 2017;42(41):25933-41.

26. Garza-Ramos U, Silva-Sanchez J, Martinez-Romero E, Tinoco P, Pina-Gonzales M, Barrios H, et al. Development of a Multiplex-PCR probe system for the proper identification of Klebsiella variicola. Bmc Microbiology. 2015;15.

27. Hubenova Y, Mitov M. Extracellular electron transfer in yeast-based biofuel cells: A review. Bioelectrochemistry. 2015;106:177-85.

28. Yong X-Y, Shi D-Y, Chen Y-L, Feng J, Xu L, Zhou J, et al. Enhancement of bioelectricity generation by manipulation of the electron shuttles synthesis pathway in microbial fuel cells. Bioresource 
Technology. 2014;152:220-4.

29. Eaktasang N, Kang CS, Lim H, Kwean OS, Cho S, Kim Y, et al. Production of electrically-conductive nanoscale filaments by sulfate-reducing bacteria in the microbial fuel cell. Bioresource Technology. 2016;210:61-7.

30. Yu M, Han Y, Cheng X, Hu L, Zeng Y, Chen M, et al. Holey Tungsten Oxynitride Nanowires: Novel Anodes Efficiently Integrate Microbial Chemical Energy Conversion and Electrochemical Energy Storage. Advanced Materials. 2015;27(19):3085-91.

31. Vellingiri A, Song YE, Munussami G, Kim C, Park C, Jeon B-H, et al. Overexpression of C-type cytochrome, CymA in Shewanella oneidensis MR-1 for enhanced bioelectricity generation and cell growth in a microbial fuel cell. Journal of Chemical Technology and Biotechnology. 2019;94(7):211522.

32. Yong Y-C, Yu Y-Y, Yang Y, Liu J, Wang J-Y, Song H. Enhancement of extracellular electron transfer and bioelectricity output by synthetic porin. Biotechnol Bioeng. 2013;110(2):408-16.

33. Wen Q, Kong F, Ma F, Ren Y, Pan Z. Improved performance of air-cathode microbial fuel cell through additional Tween 80. Journal of Power Sources. 2011;196(3):899-904.

34. Yong X-Y, Feng J, Chen Y-L, Shi D-Y, Xu Y-S, Zhou J, et al. Enhancement of bioelectricity generation by cofactor manipulation in microbial fuel cell. Biosens Bioelectron. 2014;56:19-25.

35. Li F, Li Y, Sun LM, Chen X, An X, Yin C, et al. Modular engineering intracellular NADH regeneration boosts extracellular electron transfer of Shewanella oneidensis MR-1. Acs Synthetic Biology. 2018;7(3):885-95.

\section{Figures}

\section{Figure 1}

ORP profile in ethanol fermentation by Z. mobilis(A), the comparison of cell growth and fermentation(B) and energy flow during power generation of Z. mobilis(C).

\section{Figure 2}

ORP difference (solid line) between anode and cathode chambers during bioethanol production by Z. mobilis and electricity performance comparison among water, RM medium, and Z. mobilis ZM4 (OCV: solid lines, WV: dotted lines) (A), cyclic voltammetry measurement (B) and polar curves (C) of Z.mobilisinoculated MFC and uninoculated MFC 


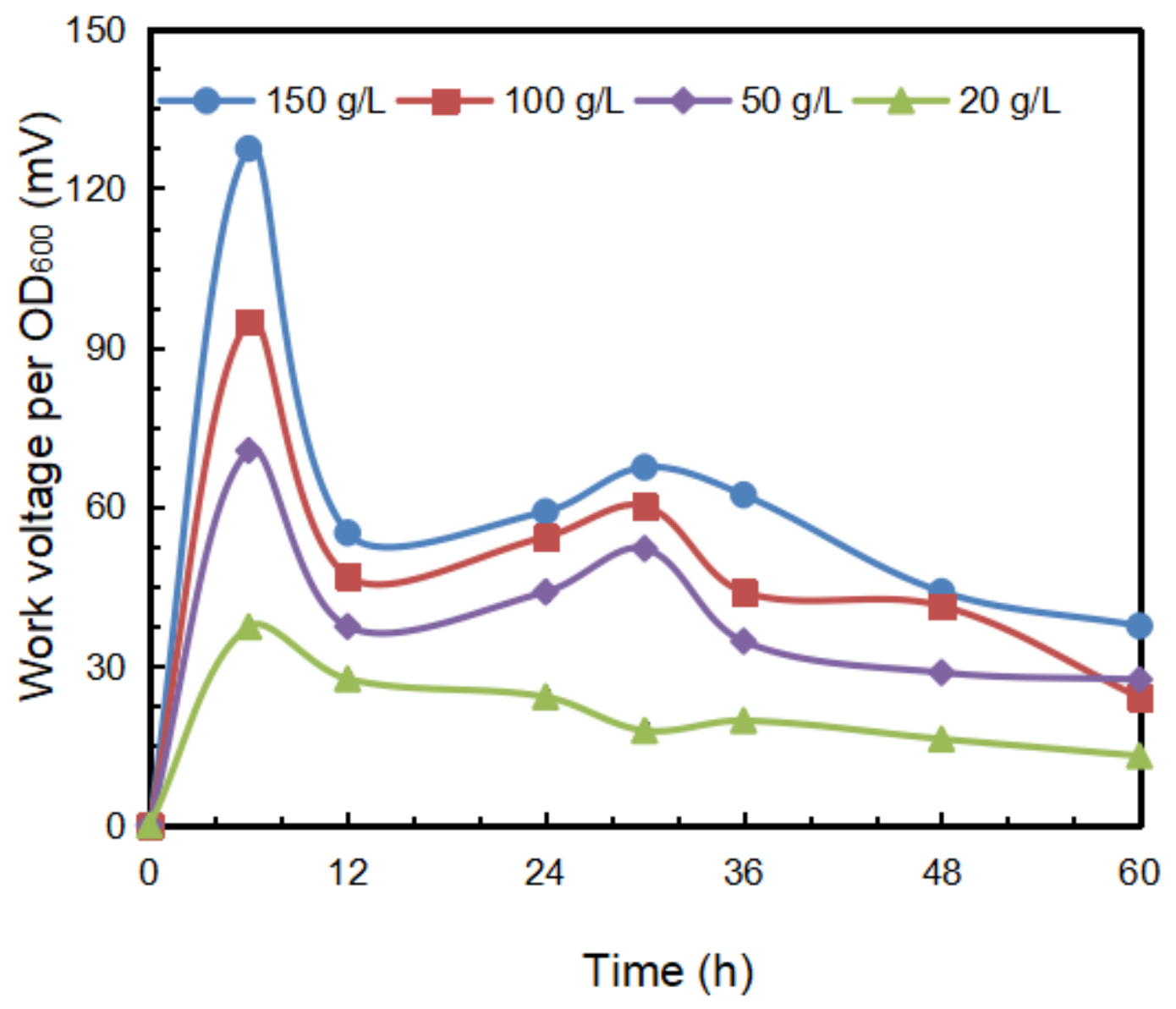

Figure 3

Specific work voltage at different glucose concentrations. 


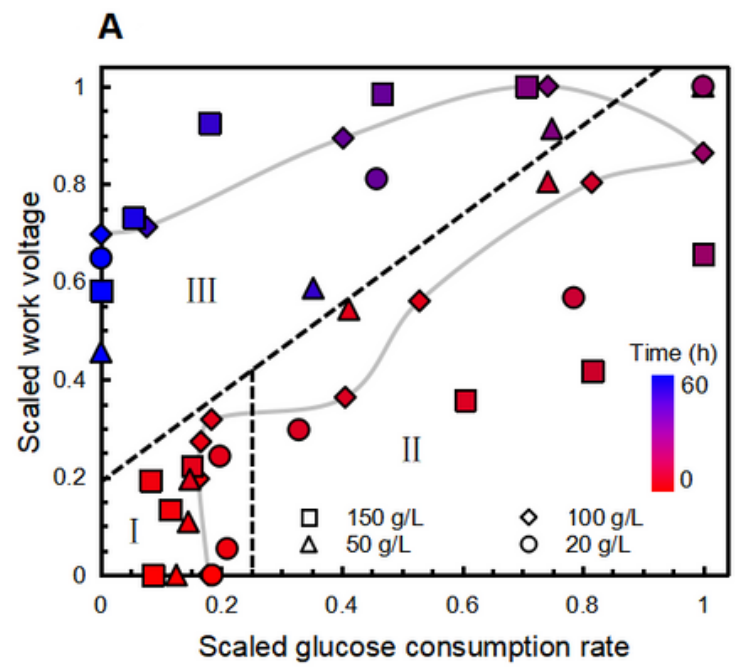

B
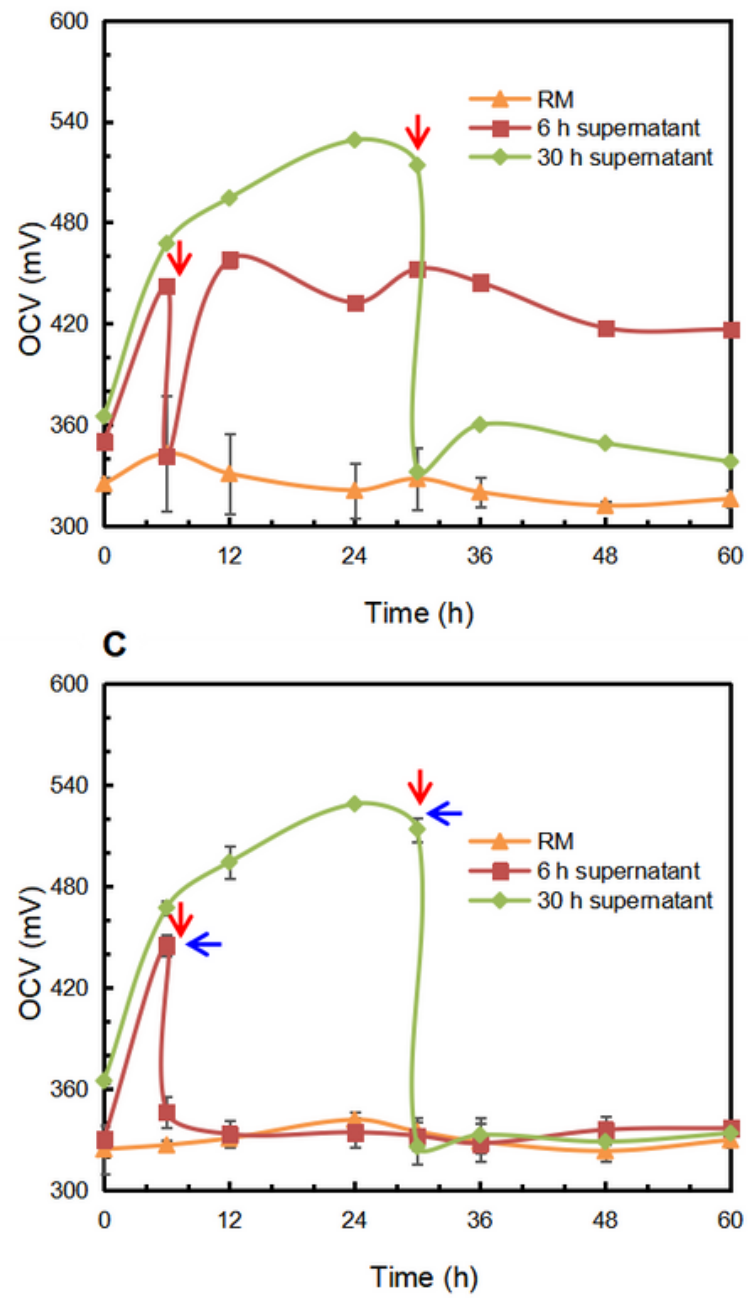

\section{Figure 4}

The correlation between glucose consumption rate and WV. Colors represents fermentation time and initial glucose were set as 20,50,100,150 g/L, among which, $100 \mathrm{~g} / \mathrm{L}$ plots were linked (A). The electricity generation process of RM, $6 \mathrm{~h}$ supernatant and $30 \mathrm{~h}$ supernatant $(B, C)$. Centrifugation was implemented at the position of red arrow and oxygen was sparged at the position of blue arrow. 
Figure 5

Biofilm formation on electrode surface, and charge transfer resistance on detached and attached electrode (A), and related electricity performance in fed-batch electricity generation process (B).
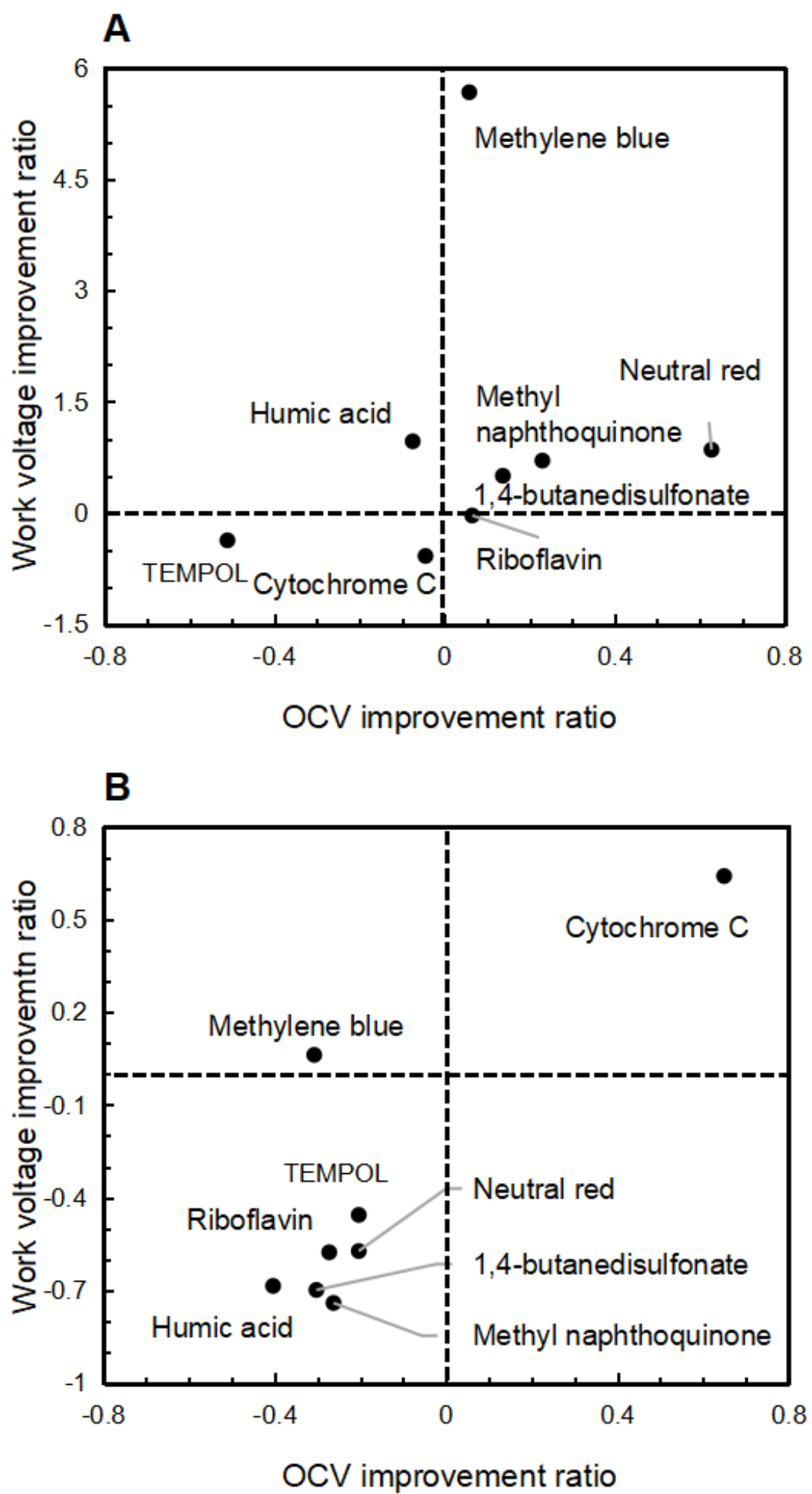

Figure 6 
Voltage improvement ratio of reagents (A) and cells (B) (Rwr: WV improvement ratio of reagents, Ror: OCV improvement ratio of reagents, Rws: WV improvement ratio of cells with reagents, Ros: OCV improvement ratio of cells with reagents)

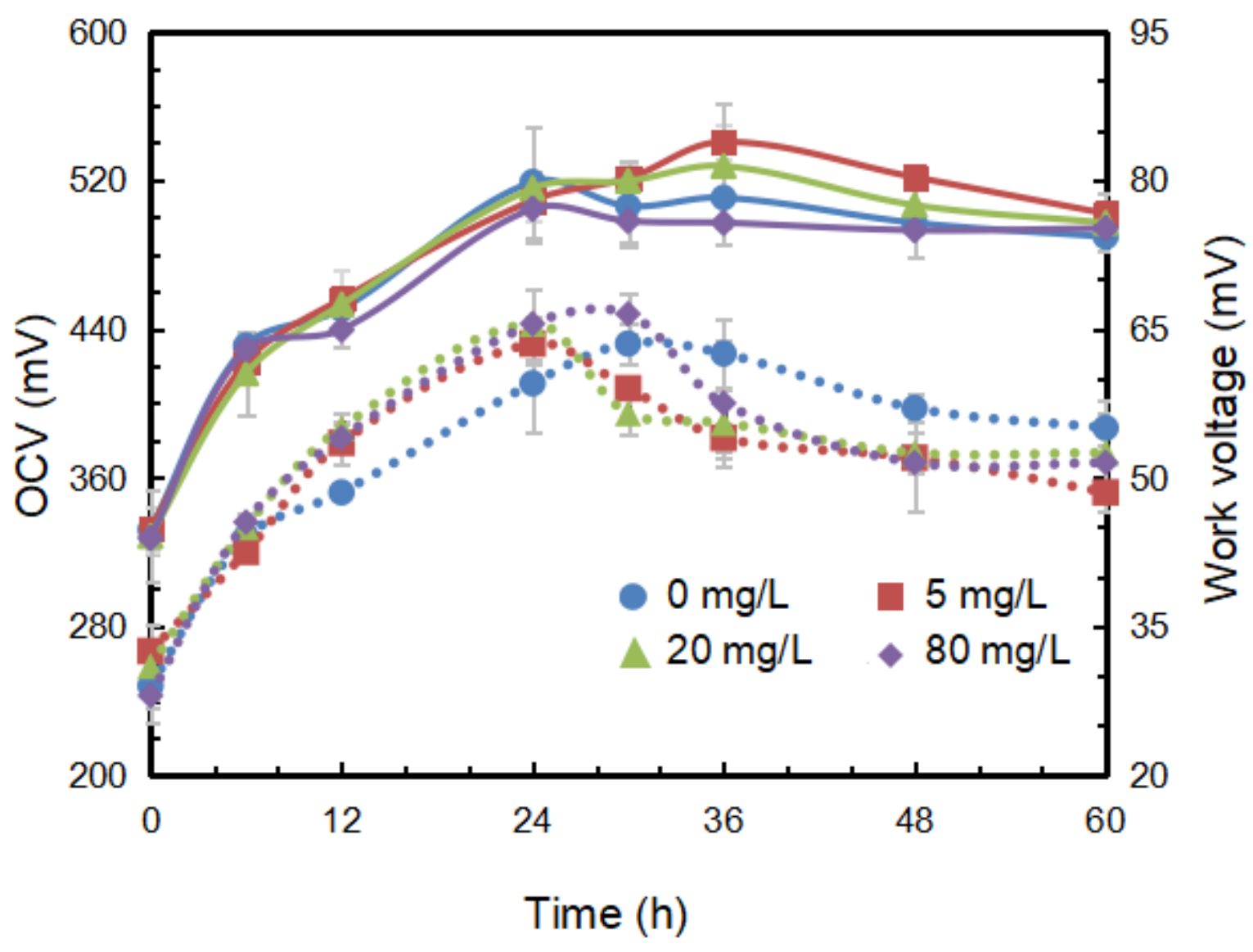

Figure 7

Electricity performance (OCV: solid lines, WV: dotted lines) of MFC with addition of Tween 80. 


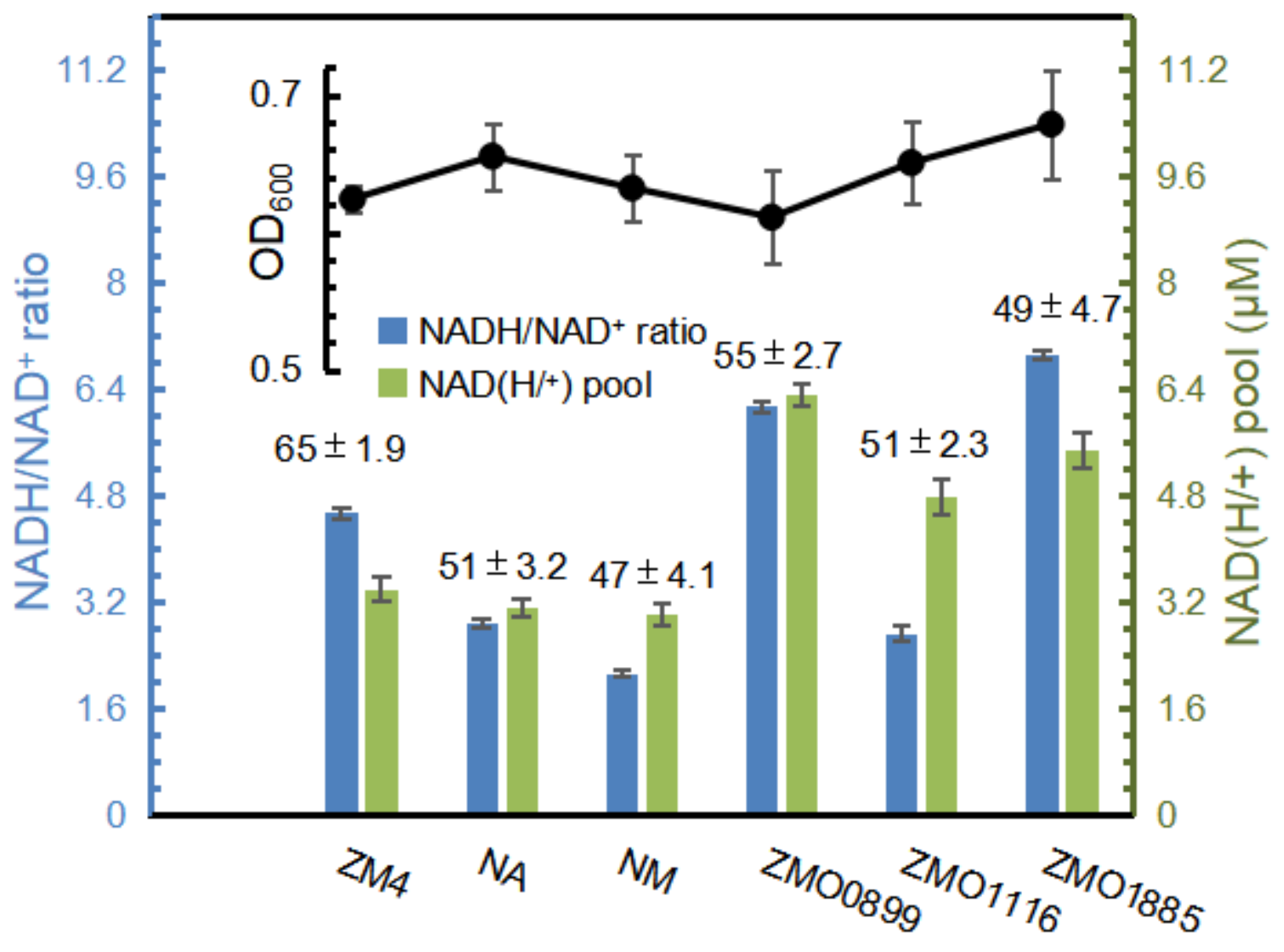

Figure 8

$\mathrm{NAD}(\mathrm{H} /+)$ pool, $\mathrm{NADH} / \mathrm{NAD}+$ ratio, biomass, and maximum WV with gene overexpression and addition of $\mathrm{NAD}+$ precursor. The data above the bar represents the maximum $\mathrm{WV}(\mathrm{mV})$ and the black line on the top of the figure compares the biomass. 


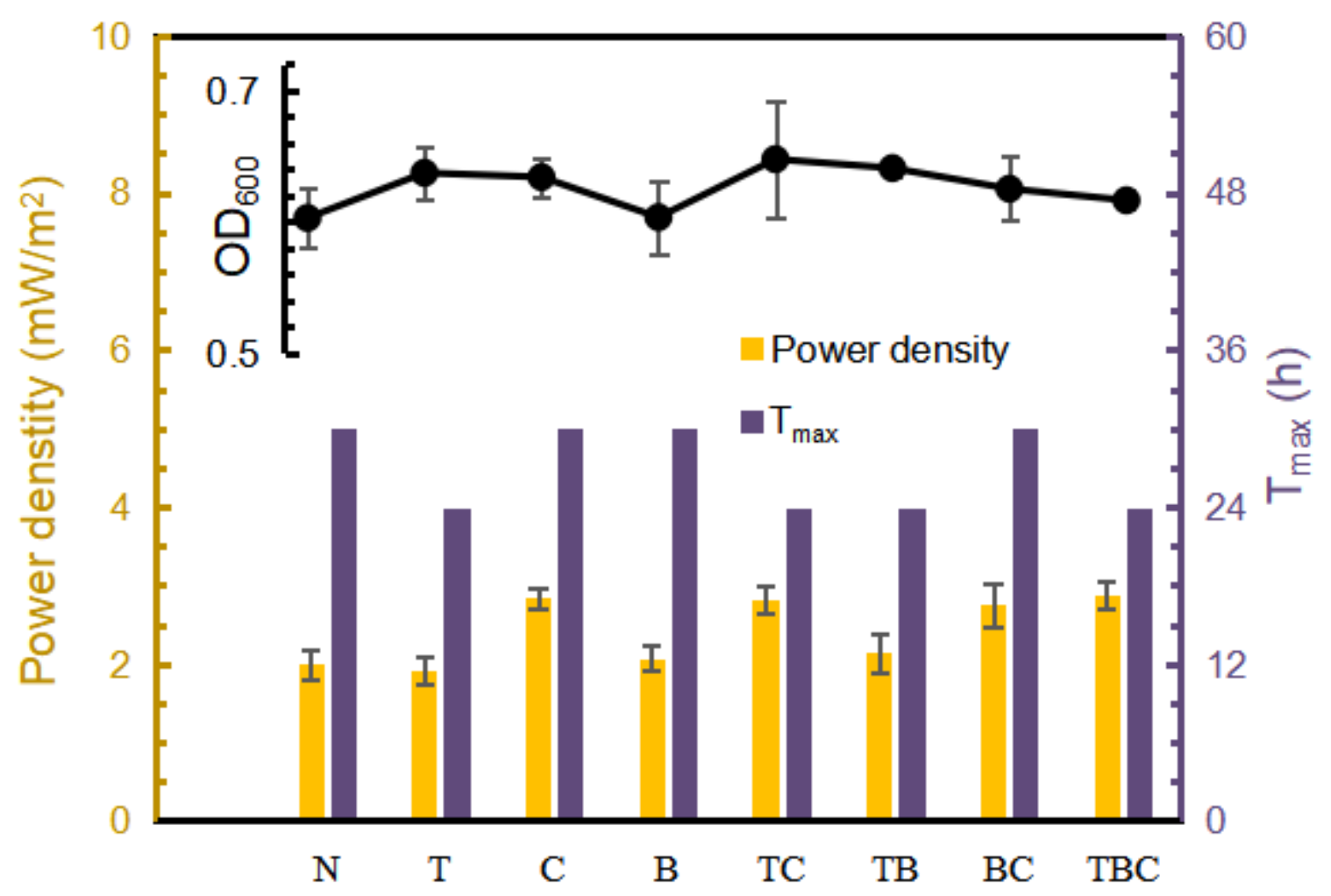

Figure 9

Maximum power densities and time needed to reach WV peaks (Tmax) in different treatment methods ( $\mathrm{N}$ no treatment, T-addition of Tween 80, C-addition of c-type cytochrome, B-biofilm removal). The combination of these letters means the cooperation of various methods and the black line on the top of the figure stands for the biomass of different treatment methods. 


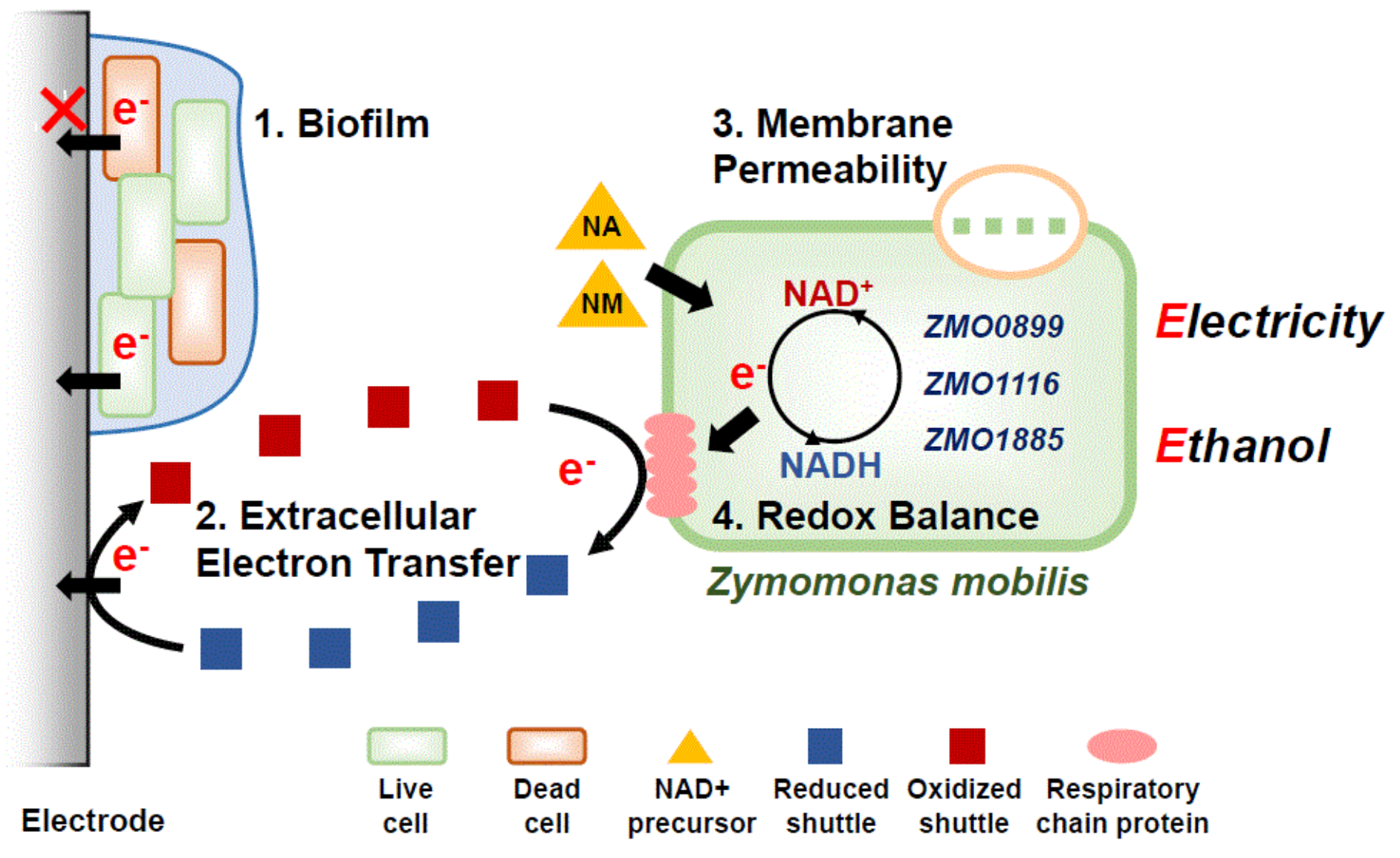

Figure 10

Schematic diagram of extracellular and intracellular strategies implemented in MFC. 